\title{
MULTI-LEVEL MODELING FOR INCORPORATING PUBLIC PERCEPTIONS INTO COMPREHENSIVE PLANNING: DOOR COUNTY EXAMPLE
}

\author{
Fahriye Hazer Sancar and Robert J. Cook*
}

\section{Introduction}

Ackoff (1978) describes planning as "... the effort to deal with sets of interacting problems as a whole." The situations in community, urban, or regional planning, where interrelationships are not perfectly understood, have been referred to as problems that are complex (Warfield, 1976), messy (Ackoff, 1981), and even wicked (Rittel, 1973).

Such problems show multiple interactions and feedback among various elements. They require interdisciplinary expertise in social, economic, political, and emotive issues intertwined with the more quantifiable elements of physical technology. They are not amenable to solution through experimentation, and components cannot be isolated effectively for separate treatment. The problem context is continuously dynamic in that the policy implementation changes the entire social system in complex and unanticipated ways.

Due to the above characteristics, such problems and their solutions are unique in time and space. Therefore, the solution cannot be tested objectively. There is no single formulation of the problem, but there may be various formulations reflecting different perspectives, each of which defines a different scope of search for a solution (Allen and Gould, 1986).

These characteristics place new demands on the planning profession in information use, interpretation of rationality, and structuring social discourse for decision making (Sancar, 1987). There is general agreementamong professionals searching for new paradigms that a method of planning to address these issues must be broadly participative and integrate a wider spectrum of systematically collected information into planning and policy situations (Sancar, 1985). Mason and Mitroff (1981) suggest that such methods must expand knowledge via participative techniques, allow for different interpretations of adverserial information components, be integrative in promoting holistic synthesis, and improve the capacity of the decision maker to understand the problem, as well as his ability to deal with social systems.

The underlying theme for a planning approach to respond to both of the above challenges is the concept of an *Respectively, Associate Professor of Landscape Architecture, University of Wisconsin-Madison; and Vice President/Director of Administration, JMB/Centers Management Company. "appreciative system," involving a constituency that is charged with policy making. Appreciation involves making judgements and evaluating their significance for the internal and external state of the system. Such judgements reflect the current views of those who make them and describe the relevant events and reactions, and their valuation under various conditions. They also disclose a "readiness" to discriminate between different aspects of a situation so as uniquely to classify and evaluate them. This state of readiness is the "appreciative system" that can be learned like any other perceptual schemata (Vickers, 1965).

Perception of a problem situation in community development may involve either internalized or externalized models. Appreciation, however, is the achievement of a special kind of perception shared by the planning group of experts and lay people. It reflects the problem situation characteristics perceived to be important and represents a collective knowledge of the situation rather than only those deemed "necessary and sufficient" by the experts. Therefore, appreciative judgment starts with the mental model of each individual, and ends with an external model containing facts and values bearing on the decisions, via cognitive processes dealing with perception and integration of information at the individual and group levels.

This paper describes the main components of a decision support system for community development that enhances the appreciative capabilities of policy-making groups by aiding them in (1) effective use of available expert knowledge, (2) integration of relevant information in problem analysis, and (3) formulation of policy options and evaluation of alternatives for problem resolution. The components of this system are a generic community development model, a problem structuring algorithm, and a situational system dynamics model. This paper is dedicated, first, to a methodological approach, with sections following on the generic model, and, guidelines for structuring/customization in developing a situational model. Finally, implementation results are given for a planning exercise in Door County, Wisconsin.

\section{The Research Procedure}

The three components of the decision support system are based on a larger procedural framework developed by Checkland (1981) and referred to as a generalized "soft" 
systems method for resolving unstructured problems. This framework, shown in Figure 1, is taken from Checkland (1981) and modified to develop the specifics of an approach to community problem solving. The procedure contains two groups of activity. These are the "real world" and "systems thinking" activities by which the real world complexity is structured. Here, the indicated structuring is done via the generation, use, and modification of externalized models.

The richest possible picture of the problem situation is built in stages 1 and 2 via brainstorming (Rickards, 1982) or the nominal group technique (Gill and Delbecq, 1982). Stages 3 and $4 a$ represent the structure of the ideas generated in the previous stages. The outcome is the model of the situation as perceived by the participants.

Among stuctural modeling techniques (Martino, 1972), Interpretive Structural Modeling addresses similar scientific-rational and social participation issues. The objectives and the advantages (Warfield, 1976; Watson, 1978) of ISM and its applications in related problems (Waller, 1975; Fitz, 1975; Malone 1975) have been given elsewhere. Here, the main function of ISM is to generate the richest picture of the situation reflecting the variety of perceptions, interests, beliefs, and interpretations of information on variables and interrelationships without a preconceived structure.

The procedures used in stages 2 through 4 a comprise the first component of the decision support system. Stage $4 \mathrm{~b}$, the second component, is a generic system dynamics model representing expert knowledge on structure and the behavior of community subsystems. The advantage of system dynamics (Sancar, 1977) and the value in the design and use of generic models (Forrester, 1961) have been discussed elsewhere. In this context, a comparison of system dynamics versus econometric models (similar to those developed by Woods and Doeksen (1983)) has been given by Sterman (1985) and hence is not elaborated here. In this study, system dynamics modeling has been chosen from the outset because it lends itself most naturally to the operationalization of the overall procedure for a participatory community decision process. Here, the generic model provides the problem solving group with an understanding of the systems potentially relevant to the community development issues.

The situational system dynamics model in stage 4d, which completes the model externalization process, is constructed by a customization procedure that integrates the structural and generic model via comparison and specification. The evaluation of the situational model takes place in stage 5. If the model is found to reflect a collective appreciation of the situation, the process continues. If not, any combination of stages 2 through 5 may be repeated.
Stage 6 involves the analysis of the scenarios deemed important, desirable or feasible by the participant group. The problem situation may be improved (stage 7) via the information and understanding obtained through the application of the entire procedure, and the process may be reiterated continuously if problems/issues continue to emerge.

The three components of the decision support system are perceived as aids in information processing and social interaction while reducing the biases inherent in human cognition. These procedures are expected to result in accumulation of knowledge about communities since the problem/decision context and its activities will be documented as part of the process. An enhanced understanding of the problem situation is reflected in the evolution of the generic model components.

\section{The Generic Model}

A generic system dynamics model contains structures and behaviors common to a general class of phenomena or systems. The identification of such general relationships may be based on theory or experiential evidence. The type and form of the information readily available to communities also are important factors in developing a generic community model. Here, system dynamics models similar in purpose and/or content, and community studies by the University of Wisconsin Extension Service were surveyed to identify recurring types of models, problems, and available data bases.

This review of the models indicated diverse structures for community systems, with no indication of a common set of variables or relationships that could form the basis for a generic model. However, two models given by Hamilton, et al.(1969) and Sancar (1977) had the widest coverage of components and relationships used to derive the model behaviors. The first was appropriate for regional level analysis and decision making, with demographic, industry, water supply, recreation, income, and electric power requirement components. The second model was designed for community development decision making, and contained the occupancy, consumption, environment, and land use components. The relevant components of the two models were combined to formulate an applicable generic structure consisting of six sectors including demographics, consumption, occupancy, employment, environment, and government policy (Figure 1).

In this generic structure, population and employment generate consumption levels that influence commercial, service, and industrial occupancy, which, in turn, drive employment. Employment in turn affects migration rates, thus affecting demographics in a cyclic fashion. The 
Figure 1

\section{Overall Strategy}

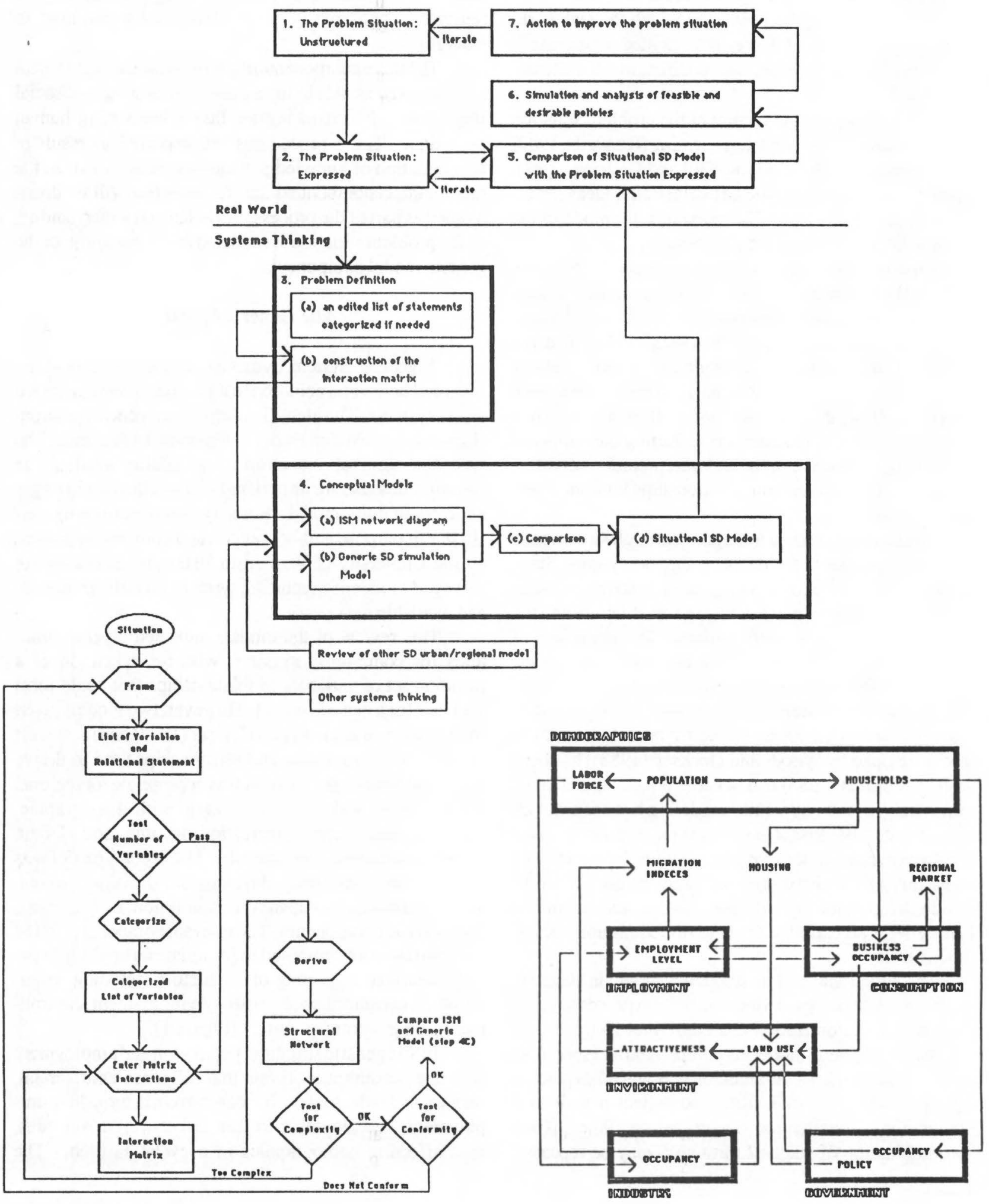


environment and land use are determined by the occupancy levels of business, industry, and residences. Government exerts an indirect influence over most of the sectors through land-use policies and economic incentives. Various environmental indices are used to reflect the attractiveness of the community in influencing migration as well as industrial and business location decisions. In the following, each subsystem is summarized without the conceptual symbols of System Dynamics and the Stella software used. The latter details have been documented elsewhere (Cook, 1987).

Demographics: This subsystem models population, households, and labor, driven primarily by in/out migration. The population is modeled using five different age groups with their rates of change affected by births, deaths, growth from one age class to the next and in/out migration. Young adult and adult migration is determined through the unemployment rate and housing availability. Migration of the elderly is determined through an environmental attractiveness index based on congestion, housing, and services.

Population is converted into households using a persons-per-household ratio, with the households categorized into high, middle, and low income groups based on the current employment rate. The percentage of each age group entering the labor force is determined by the unemployment rate. Household purchases of convenience, shopping, specialty, service, and entertainment goods drive the consumption subsystem in which each income group has a different consumption pattem reflected by its expenditure multiplier (Sancar, 1977).

Occupancy: The occupancy subsystem has five household-serving businesses (convenience, shopping, specialty, service, and entertainment) as well as businessserving enterprises, and industrial, agricultural, and governmental units. For household-serving businesses, consumption of each category of goods determines the square footage of occupancy for that category. Business-serving occupancy is proportional to household-serving businesses. Industrial and agricultural occupancies are driven by external demands and attractiveness indices. The government occupancies are converted to employment levels via employment-per-square-foot multipliers.

Land Use: This is a closed subsystem in which land is first converted to vacant status from other general uses such as agriculture, open space, residential, commercial, or industrial, and then may be reclaimed for an alternative use.

Government Sector: This independent sectormodels land use and environmental policies. The development pace is influenced by the construction multipliers or by agricultural land conversion limitations. Initial values of policy multipliers are unity, with actual values to be deter- mined during customization.

In all the sectors above, functional relationships between variables are represented by a series of multipliers. Their operationalization is via empirical data on past trends, causal influences, expert opinion, or by conducting situational research on public responses to environmental change. Ordinarily, the multipliers based on expert opinion are operationalized and included in the generic model, while the rest are determined during participatory customization of the model.

\section{Structuring}

Structural models portray the situational features and their interrelations through graphic techniques and are used to build the conceptual bridge between the mentaly prose models and the dynamic models, and to enhance and document the thought process. Here, structuring is done using Interpretive Structural Modeling (ISM) with additional enhancements to encourage creativity and improve inferences/judgements. The philosophy, advantages, and appropriateness of the technique in the class of problems considered has been discussed elsewhere (Simon, 1969). In this study, the main function of the ISM prior to simulation modeling is to reflect a collective appreciation of the situational context.

The implementation steps of ISM (Wilson, 1982) are determination of the variables and the relational proposition, generation of the interaction matrix, and derivation of the structural network. There are alternative ways of taking these three steps, each of which has different impacts on the final outcome in terms of the additional objectives of (1) generating creative system design options, (2) learning and avoiding inferential bias through information search/interpretation on facts and values relevant to the situation, and (3) generating and documenting participant interaction and negotiations in modifying different interpretations of reality and perspectives.

Incorporation of the above objectives into classical ISM is the modification introduced by the authors to obtain five explicit decision points during structuring (Figure 1). These decision point activities are framing, categorization, interaction specification, network development, and customization, as described in the following.

Framing: The outcome of the first decision point is a list of variables and a relational proposition. During framing, each question or probe used to generate the list of variables thought to be relevant or important by the participants represents a different way of "framing" the situation, i.e., a different perspective. The choice of a perspective and the scale and specificity of the problem statement may enhance or limit a group's problem-solving capabilities. 
Whatever the scale and specificity of the perceived situation may be, there are two opposing perspectives of framing-problem analysis and system design (Sancar, 1983). When the situation is "messy," the former perspective is dominant among the participants. However, given the advantages of adopting the latter perspective (Nadler, 1970; Ackoff, 1978; Checkland, 1981; Sancar, 1983), if the list of statements turns out to be problems, the opposing perspective may be introduced by "re-framing" (Bandler and Grinder, 1982). Similarly, dominant, self-contained perspectives based on the cognitive styles of individual participants (Mitroff and Turoff, 1973), motivational factors, and past involvement with the situation can be avoided if ideas are generated alternately by all group members. At this stage, the statement list must be kept long and diverse through brainstorming (Rickards, 1982; Warfield, 1975).

The relational statement provides the conceptual building block in matrix interaction specification, representing the relationships to appear in the situational model. These statements must be posed to be consistent with framing. Examples of relational statements are phrases such as influences, is related to, and helps/hinders.

Categorization: This activity introduces the simplest way of structuring a list of statements or ideas by discussions that help the group gain a common understanding of terms and definitions. The resulting matrix categories become an anchor for the group during interaction on specification of elements in the next step. The elements can be categorized by making similarity judgements to place elements into clusters. Discussion prior to assignment of elements may result in modification and editing of the original statements.

Matrix interactions: In this stage, the existence and strength of interactions among issues/elements are specified by causal inferences/judgements of participants. The latter may be affected by framing, the information available, and the data interpretation procedures. Generally, the participants are quite successful in making inferences by judgemental heuristics. The observed shortcomings and biases in judgement are due either to inappropriate use of heuristics or the inability to adjust initial judgment with new information. The conditions/requirements to be met to enhance this latter adjustment capability and to reduce biases have been discussed by Nisbet and Ross (1980). An awareness of various biases and their minimization by framing and data presentation using "assumptional analysis" techniques (Mason and Mitroff, 1981) in organizing parts of arguments, such as warrant, backing, claim, and rebuttal, while interpreting information, also will lead to more enlightened inferences.

After the entry of the matrix interactions, their impor- tance ratings (which can be determined by the appropriate "assumptional analysis") may be used to simplify the matrix to between three and five interactions per column (or row) and avoid complicated networks lacking conceptual clarity and visual impact.

Network development: At this decision point, ISM is used to convert the interaction matrix into a "directed graph," showing the hierarchy of variable clusters and their relationships, and then into a graphic network representation. The general features of the networks are discussed with respect to their acceptability in representing the situation. If found acceptable, the group then is ready to build a situational model based on the networks to generate and test alternatives.

Customization: The customized situational model is generated by transposing the elements of the completed networks into a system dynamics model by a participatory comparison of (1) the generic model sectors with the interaction matrix variable categories and the structural networks, (2) the major feedback loops and instrumental variables with those in the networks, and by inclusion of (3) additional sectors and relationships required. After completing the situational model, it can be used by all involved to generate and test policy options and to experiment with and test the model.

\section{Evaluation of the Procedure}

The modeling techniques and procedures given in the preceding material provide a participative avenue for (1) voicing opinions and considering opinions voiced by others with an awareness of the interrelated nature of the entire set of concems, and (2) structuring information to describe the problem situation accurately. The operationalization of this customized procedure will vary depending on the circumstances and reasons for its application. The expected benefits of the procedure, common across applications, must be expressed in measurable terms that help generate information useful for understanding the degree of success in the specific application, and of the procedure. Three concepts that can be used for such an evaluation are cognition, creativity and social interaction.

Cognition is an individual mental process involving active manipulation of information encompassing perception, learning, memory, and thinking for the purposes of problem solving (Mayer, 1983). Active participation improves understanding and knowledge about systems/ issues modeled. The judgments of the participants on improved understanding of situations, on the new information gained, and on the clarity of the outcomes/models are the measures for this concept.

Creativity should be evident in both the process and 
the product. The essential feature of this concept is that participants grasp previously unrelated but essential parts of a problem and see them in a new pattern in creating a novel and appropriate product. The heuristic process that the group uses to obtain the product also elicits an aesthetic response (Amabile, 1983). During problem formulation or structuring, solutions will be implied rather than precisely defined so as not to limit the possibility of novel solutions. Measures of this concept therefore should assess solution implications and the level of enjoyment/satisfaction of participating individuals.

Social interaction is necessary for participation in the generation, sharing, clarification, and evaluation of ideas; italso will increase awareness of the concerns of others and satisfaction with personal contributions. Thus, the relevant measures may be in the form of an awareness or satisfaction parameter.

\section{Implementation}

The modeling approach described in the preceding section was implemented in a comprehensive planning program of the Door County, Wisconsin, Planning Department. The objectives in implementation were both theoretical and practical in nature, and were emphasized by both the researchers and the county planner. The research objectives were to obtain measures of cognitive, creative, and social interaction processes that are facilitated by the procedures. Evaluation of the clarity of the structural model's (to participants), its comprehensiveness, capability of promoting understanding, solution implications, and similarity to the Generic System Dynamics Model also was important. The practical objectives in planning were "... to provide public opportunity to identify issues of concem in a structured, thought-stimulating format ..." and "... to test the accuracy of planners' perceptions of public issues ..." (Door County Resource Planning Committee, Resolution No. 85). For the planner, representativeness of the issues to be revealed by structural modeling was of primary importance.

The county was divided into five homogenous areas based on regional differences and travel distances for the participants. The participants were volunteers who responded to a newspaper advertisement announcing the start of the comprehensive planning project and asking for representatives of various interest groups to take part in a nine-hour exercise. This advertisement is shown in Figure 2. Given the political realities of the situation, selecting participants from volunteers, rather than randomly, was preferred by the planner. While such self-selection limits the generalization of results to a wider population, this is more representative of real-life constraints in typical planning situations, and of actual instances in which such modeling approaches are likely to be used.

There were two reasons for identifying the various interest groups and affiliating the participants with one or more of them. First, an ideal set of participants would contain representatives from all interest groups to ensure the inclusion of all possible issues and points of view. Second, since the workshops were intended to incorporate all issues and concerns in the final product, people with similar interests could be grouped together and those with opposing views could be separated to avoid premature focus on points of contention. Interest group affiliation for those in attendance at all three meetings is illustrated in Table 1.

In the first meeting, after completing an initial questionnaire on organizational affiliations and prior experience with public meetings, the participants were asked to generate lists of desirable qualities, the corresponding

Table 1

Workshop Participants by Geographic Area and Interest Group Affiliation

\begin{tabular}{llcccccc}
\hline \hline Interest Group Affiliation & Area 1 & Area 2 & $\begin{array}{c}\text { Area 3 } \\
\text { number }\end{array}$ & Area 4 & Area 5 & Total \\
\hline Agriculture/Fisheries & 0 & 0 & 2 & 1 & 1 & 4 \\
Business & 1 & 6 & 2 & 2 & 1 & 12 & 8 \\
Government & 0 & 4 & 1 & 1 & 2 & 8 \\
Real Estate/Development & 0 & 4 & 1 & 2 & 1 & 28 & 4 \\
Environment & 5 & 9 & 8 & 4 & 2 & 5 \\
Historic/Cultural & 0 & 4 & 0 & 0 & 0 & 0 & 5 \\
General Resident & 0 & 1 & 3 & 1 & & 7 \\
Total & 6 & 28 & 17 & 11 & 7 & 69 \\
\hline \hline
\end{tabular}




\section{BEPART OF DOOR COUNTY'S FUTURE}

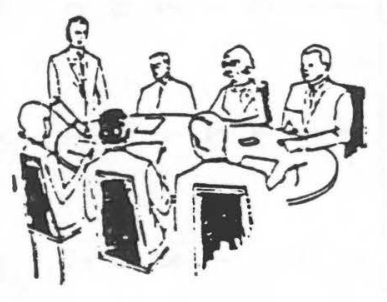

A countywide planning project sponsored by the Door County Board of Supervisors is about to begin. Cons E INVITED TO PARTICIPATE IN THE CITIZEN INVOLVEMENT PROCRAM where your perceptions regarding the quality of life in Door County and your concerns and interests relating to Door County program will be conduced with the assistance of the University of Wisconsin Department of Landscape Architecture.

Group participation sessions will be held in each of five areas of the county. Each group pail cipsist of people will be held in each of five areas of the con in

1. Qualities of Door County which are found to be desirable and enjoyable.

2. Opportunities for entancing those qualities found to be desirable and enjoyable.

3. Distinctive Door County resources.

4. Concerns about those qualities, opportunities and resources.

The process requires that the same peoole participate in all three sessions. Each session lasts about three hours. Thus. each participant will need to commit about
nine hours of time to the activity.

SCHEDULE OF SESSIONS

Area 1 - September 13 and 27 and October 11, 1985; 3:00 p.m. Washington Island Community Center.

Area 2 - September 19 and 28 and October 12, 1985: 9:00 a.m.; Liberty Crove Town Hall, 11161 Old Stage Rood.

Area 3 - September 14 and 28 and October 12, 1985; 2:00 p.m.: Sevastopol High Sehool.

Area 1 - September 15 and 29 and October 13, 1985; 12:00 noon: The Commons, Sturgeon Bay High Schocl, Sturgeon Bay.

Area 5 - September 15 and 29 and October 13, 1985; 1:00 p.m. Southern Door High School.
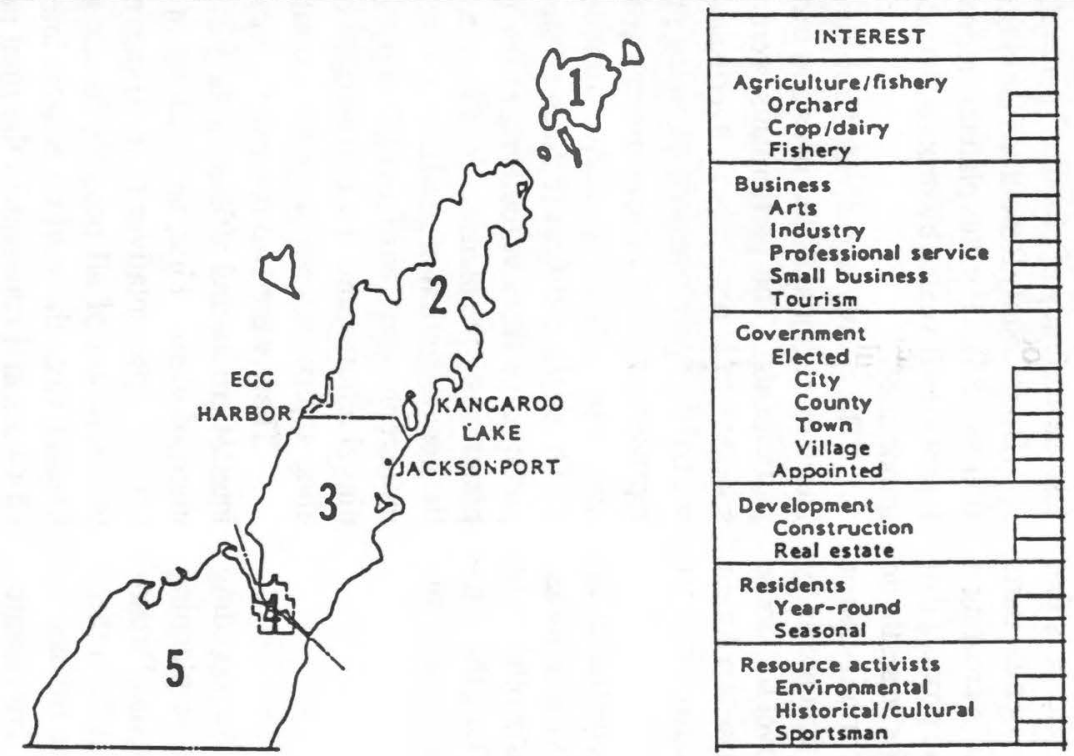

On the above map. please circle the number which most closely designates the area of Door County in which you live or work. And on the chart, please place an $(X)$ place an $(x)$ in more than one box if you want 10 indicate multiple interests. Organizations involved with the listed interests may want to participate in the process by assigning a representative.

IT IS IMPORTANT THAT ALL REOUESTS TO PARTICIPATE BE RECEIVED OR CALLED IN BY FRIDAY, SEPTEMBER 6, 1985.

Please place the part with the map and chart along with your rame, address.

$$
\begin{gathered}
\text { Door County Planning Departmen } \\
138 \text { South Fourth Avenue } \\
\text { Sturoeon Bax, W1 } 54235-0067 \\
\text { Attention: Robert w. Florence } \\
414 / 743-5511
\end{gathered}
$$

Kame

तबdress

Teephone Number 
resources, and issues/concems relating to them. The individuals then were assigned to groups based on their stated interests (such as business, environment) to avoid confrontation between competing interests and to favor unhindered discussion. Each individual shared his/her issue statements with others in a small group. The statements were read collectively, edited for clarity and categorized under major headings chosen by the group. After categorization, all participants weighted the issues as to importance and identified those whose existence they felt was most certain, based on the available information. The importance judgments provided a record of concerns across all participants and groups. The certainty judgments identified the issues for which information was available, and on which decisions could be made. In doing so, however, the participants also exposed issues or problems on which little or no information existed. If these problems were thought important, an information search was to be made to verify both the existence and the relative importance of the issue.

For the second meeting, the facilitators re-edited and condensed the issue statements, categorizing them under the headings: employment, consumer, land use, infrastructure, environment (natural, scenic, cultural), and govemment. The participants completed the interactions matrix by pairing each issue with all others. The task was to consider each pair of issues, to identify those in which influencing relationships existed, and to determine the influences to include in the most critical set. These results were used by the facilitators to develop network diagrams showing the interrelations among all issues and problem statements for all five areas of the county. The initial matrix resolutions were done using the ISM-UNI (Wilson, 1982) software. The graphic representation was generated manually using an heuristic algorithm. The final diagrams represented the combined thinking of the participants in the respective areas, as exemplified by the structural model obtained for Area 3 (Figure 3).

In the third meeting with each set of participants, the above results were presented and discussed. The facilitators first described the rules for interpreting the diagrams. Then, specific interpretations were shared with the group and used to develop possible action scenarios that included the major issues defined during the earlier meetings. After further discussion and a short presentation by the county planner on the continuation of comprehensive planning efforts, the participants were asked to: (1) reformulate the major problem(s) facing the county, (2) identify the individual or group responsible for the solution(s), (3) define the desired outcomes and (4) recommend specific actions. The participants then completed a second questionnaire on their evaluation of the process and results.

The model was customized in three steps. First, the overall themes represented in the ISM networks were identified and incorporated in the generic model. In the next step data were acquired to initialize the model. Finally, the multipliers were formulated. In this implementation, all three steps were performed by the authors, whereas ideally, user participation would be expected at this stage. The resulting situational model then was presented to the county planning staff and evaluated by them as to clarity, breadth, and usefulness in the planning process.

\section{Results of Implementation}

The above implementation offered three types of results relating to: characteristics of (1) participants and (2) the generated models and (3) evaluation of the models/ procedures used.

\section{Participant Characteristics}

Two questionnaires assessed (1) participants' involvement in community affairs and familiarity with public meeting forums, (2) their assessment of the process used and the results obtained during the three meetings, and (3) such relevant demographic information as age, income, and residential status.

The responses showed the entire group to be quite active in community affairs and public meetings. Only eight of the 69 claimed no affiliation with any organization, while 39 claimed membership in three or more. When they were asked how many of the participants were known to them, the group averaged just over five. The ratio over all groups was just under 30 percent, indicating that, on the average, each participant knew three out of every 10 people in the room. The average number of personal contacts per month between an individual and his/her acquaintances was just under five.

Most participants indicated some level of post-high school education. The average number of years was 4.6, and 47 of the 69 had earned at least one college degree. On the average, the group was well-educated.

Regarding participant demographics, the majority were over age 45, married, female, and of middle to uppermiddle income status $(\$ 15,000$ to $\$ 50,000$ annual household income). Most of the participants currently lived either in a rural or a small community setting, owned their homes, and were year-round residents. A fair number of participants were relatively new residents, with 20 of them having lived in the county for five or fewer years. 
Structural Model for Door County Area 3 Showing Numbered Issue Statements and Their Interrelations

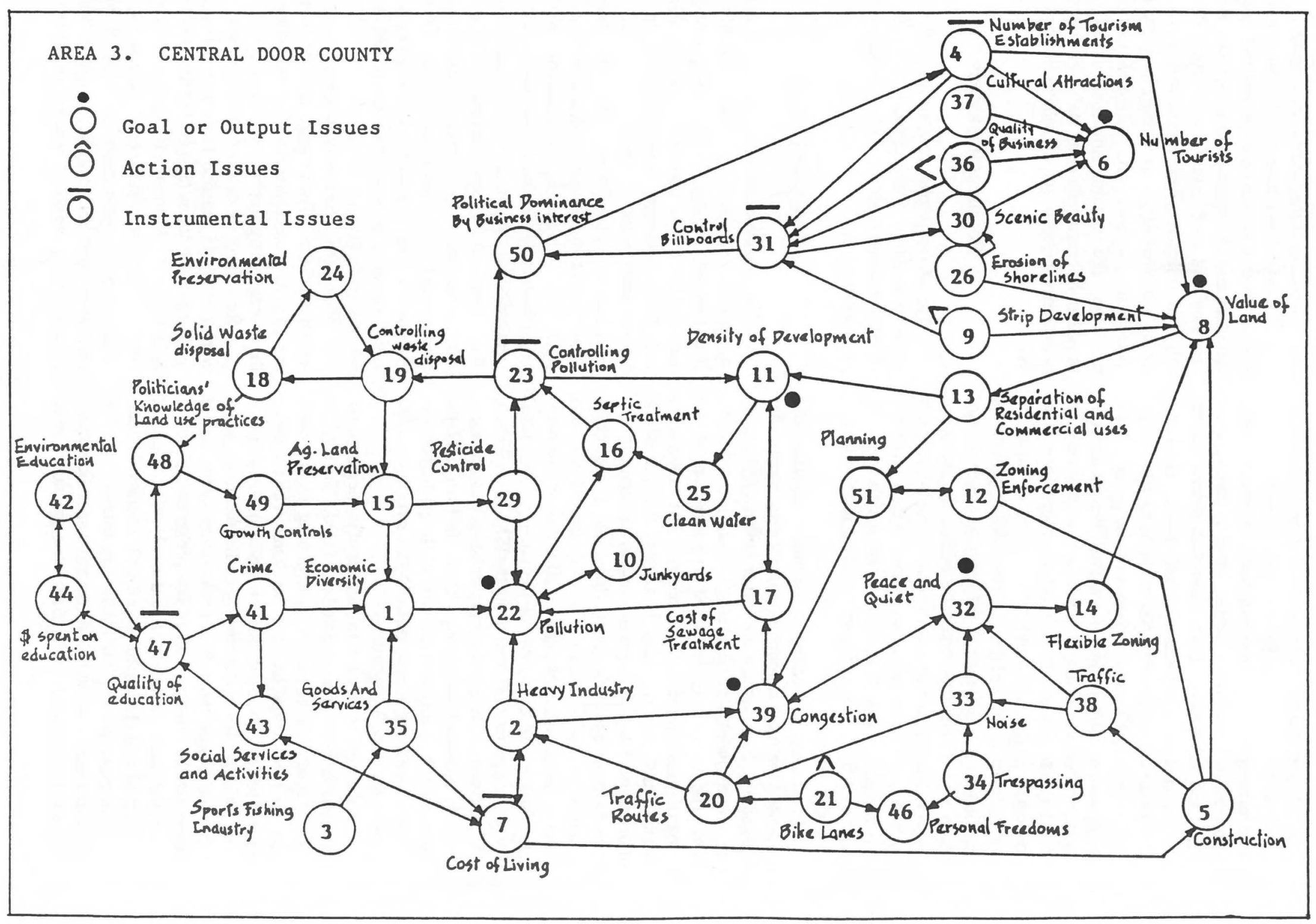


Multi-level Modeling for Incorporating Public Perceptions into Comprehensive Planning: Door County Example

Figure 4

Simplified Network Diagram

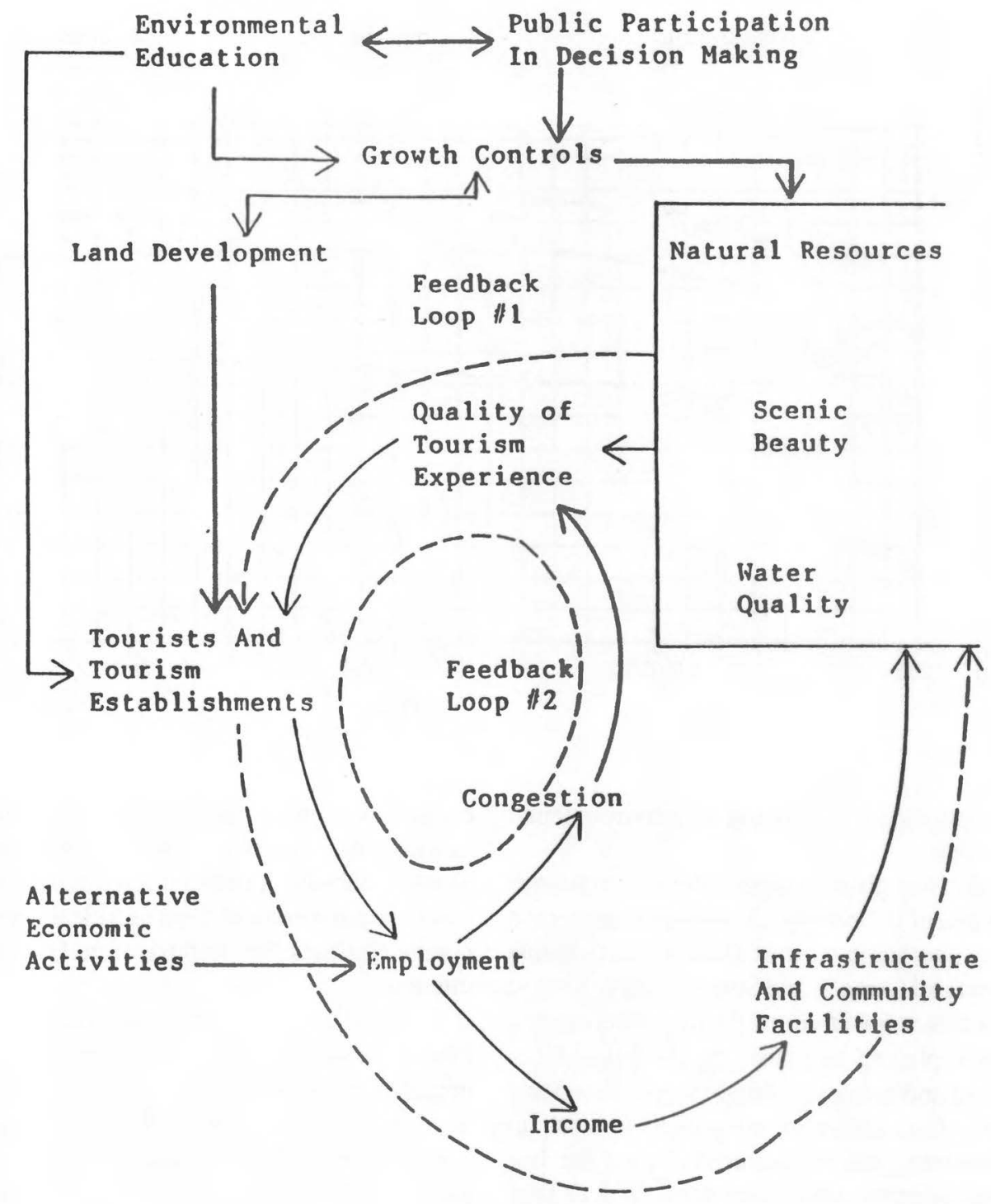

\section{Network Characteristics}

During the workshops, it became clear that certain concerns were common across Door County and that the majority of the participants felt a sense of urgency. Without exception, residents from all five geographic areas perceived an impending crisis if development activity were allowed to continue without adequate environmental safeguards to preserve unique natural and cultural resources. Current zoning laws were thought to be inadequate and their enforcement poor to non-existent. Sanitary waste treatment sytems currently in use were viewed as disfunctional or insufficient and a threat to ground and surface water resources. Many held the tourism industry responsible for county-wide ills, perhaps because of its high visibility through commercial establishments, seasonal congestion, and billboard advertising. Finally, a significant number of participants shared the perception that local officials and decision-makers were not aware of public opinion or did not heed it, and had failed to educate 
Flgure 5

Baseline Model-Run 1

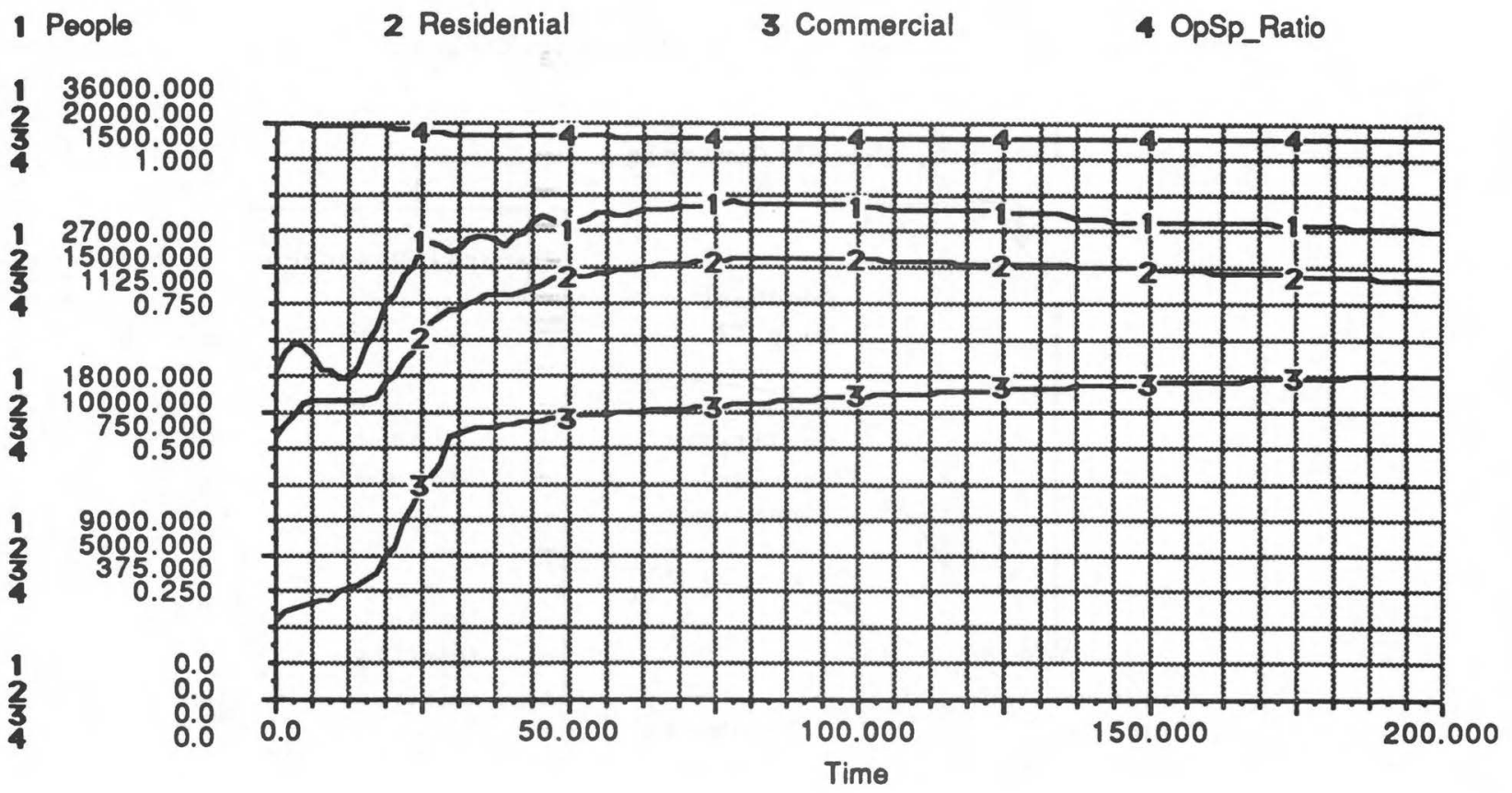

themselves in proper land use planning and environmental protection practices.

Attention also was given to geographic differences in the various sections of the county. The five areas studied differed from one another in various aspects. Participants from the northern third (Area 2) and Sturgeon Bay (Area 4) regions shared a desire for environmental protection and controlled growth, placing emphasis on the balance between such control and economic opportunity. Residents of Area 2 sought infrastructure improvements to catch up with the development that has occured during the last several years, and assurance that all systems such as land management, zoning enforcement, waste disposal, and traffic control will be made satisfactory prior to additional development.

Sturgeon Bay participants showed a certain expertise in identifying the high social costs of uncontrolled development and the means of placing such costs with developers. This community, more than any other in the county, is in a growth mode; however, the participants emphasized the need for adequate controls. The community also wished to see a convention center and additional hospitality businesses along its waterfront. The need to promote the community to small industries that would provide in- creased employment and tax revenues that do not fluctuate as much as those from heavier industrial establishments was emphasized. Further improvements in various downtown areas to promote them as a clean, enjoyable places to conduct business and purchase retail goods was of primary interest.

Participants from the central and southern portions of Door County (areas 3 and 5, respectively) emphasized the negative spillover effects of tourism facility concentration in other areas of the peninsula. Congestion, damage to the environment and the number of tourists were important issues in both sets of meetings. Participants from the central area felt that their peace and quiet were disturbed by excessive strip development along county highways. The quality of commercial establishments was considered inadequate in appearance and/or in goods sold. Residents from southern locations saw excessive residential development and sought the enforcement of zoning laws and the implementation of growth controls. Concern about the visual impacts of billboard advertising was voiced most strongly in these two areas where such advertising was prominent.

Washington Island (Area 1) residents viewed their community as a closed system with limited resources. 
Multi-level Modeling for Incorporating Public Perceptions into Comprehensive Planning: Door County Example

Figure 6

Baseline Model-Run 2

1 Ind_Loc_Index

2 Ind_Units

3 Vis_Attract_Index

4 Visitor_Days

$\begin{array}{rr}1 & 1.000 \\ 2 & 10000.000 \\ 3 & 1.000 \\ 4 & 2400000.0 \\ & \\ 1 & 0.750 \\ 2 & 7500.000 \\ 3 & 0.750 \\ 4 & 1800000.0 \\ & \\ 1 & 0.500 \\ 2 & 5000.000 \\ \frac{2}{3} & 0.500 \\ 4 & 1200000.0 \\ & \\ 1 & 0.250 \\ 2 & 2500.000 \\ \frac{2}{3} & 000000 \\ 4 & 6000000 \\ & \\ 1 & 0.00 \\ 2 & 0.0 \\ \frac{2}{3} & 0.0 \\ 4 & 0.0\end{array}$

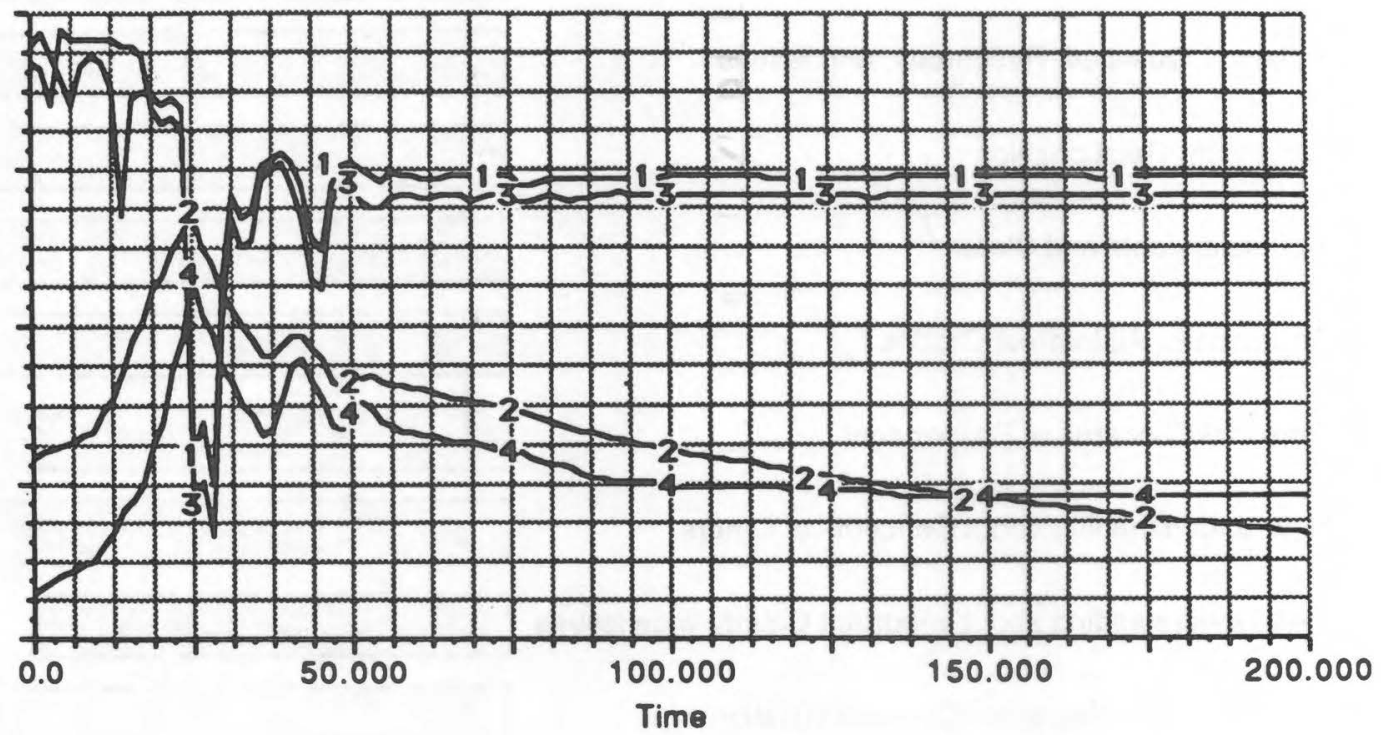

Land use patterns and waste disposal measures were distinct issue. ${ }^{3}$ Goals were to preserve both the natural resources and the unique way of life on the island. The residents were anxious to have additional economic opportunities, but believed current patterns of heavy day-use by tourists created more problems than benefits. Increased overnight visits were desired in order to capture some of the revenues now channeled to mainland businesses. Small, clean industry on a scale compatible with existing population levels and infratructure was encouraged.

A review of major issue categories and specific problems believed important throughout the county yielded the following outline of policy issues needing further attention:

1. Land use: location, density (lot size), amount of development, public access (shorelines, unique areas, recreation opportunities);

2. Water resources: ground water, surface water, shoreline pollution;

3. Preservation of unique natural and cultural resources;

4. Scenic beauty: billboard advertising, architec-

tural appearances, roadsides; and

5. Public involvement in decision making: public participation, environmental education.

While the five areas had different sets of problems or problem emphases, these were interrelated through a series of complex impacts. The major themes common to all five areas are shown in the diagram in Figure 4, where two major feedback loops are evident. In the first loop, natural resources provide outstanding tourism experience, attracting tourists and tourism establishments. This leads to added employment and income, together with unwanted new infrastructure and development that may adversely impact the resource base. As a spin-off from this loop, increased tourism increases land development and, in the absence of growth controls, adversely affects the resource base. These feedbacks are expected to lead eventually to a depressed tourism industry. The cycle can be broken if communities do not invest in new infrastructure and other public facilities, or do so sparingly with effective growth controls. A steady state can be attained by careful planning and control of infrastructure and related facilities, and by judiciously locating them to direct new development to the 
Table 2

Summary of Participant Evaluations of the Procedure and the Diagrammed Results

\begin{tabular}{|c|c|c|c|c|c|c|}
\hline Response Scale & Low 2 & 3 & 4 & 5 & 6 & $\begin{array}{r}7 \\
\text { High }\end{array}$ \\
\hline Broad Outlook & & & & & 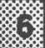 & \\
\hline Solutions & & & (4) & & & \\
\hline Relevant Qualities, Resources, and Issues & & & & & 6 & \\
\hline Significant Relationships & & & & & 6 & \\
\hline Understandable and Clear & & & & & 6 & \\
\hline Concerns of All Interest Groups & & & & & 6 & \\
\hline Personal Concerns of Respondent & & & & & & 7 \\
\hline New Understanding about Concerns of Others & & & & 柆 & & \\
\hline New Understanding about Important County-wide Issues & & & 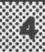 & & & \\
\hline New Understanding about Complex Relationships & & & & 樂 & & \\
\hline Enjoyed Participating & & & & & & 7 \\
\hline Satisfied with Own Contributions & & & 18 & & & \\
\hline
\end{tabular}

Note: Graphs indicate mean responses; numbers indicate most frequent responses.

areas that need it.

The second feedback loop represents the response of tourists to the attractiveness of the area and the tourism experience quality. As congestion increases, perceived quality declines. If congestion becomes excessive and protective measures do not maintain the quality of experience now found in the county, the area gradually will lose its attractiveness, tourism activity will decline, and the economy will be depressed.

\section{The Situational Model}

The model was extended by adding a lodging sector, driven by a new key sector, "visitor days," to the occupancy subsystem. Lodging units were converted from commercial occupancy as a response to an increase in visitor days and, in turn, generated employment. The visitor days sector was influenced mainly by an attractiveness index that was a composite of a general quality index, the availability of services, lodging, and an open space index.

\section{Model Testing}

The model was tested by comparing predicted behaviors with existing data on major variables for the past 20 years, and by examining the acceptability of trends generated in the long-term toward an equilibrium state. The long-term behavior of the system is given in Figures 5 and 6 , showing population, land use, and visitor day variables. These results confirm the perceptions of the public, and have interesting implications for policy development since the model does not show a major collapse in the key sectors as compared to their present performance levels. However, the model points out the possibility of an unstable 
Table 3

Within- and Cross-Interest Group Comparison of the Percent of Importance Scores Given to General Problem Categories in Meeting 1 with the Percentage Frequency of their Mention in Final Problem Formulations in Meeting 3

\begin{tabular}{|c|c|c|c|c|c|c|c|}
\hline & & \multicolumn{2}{|c|}{$\begin{array}{l}\text { Agriculture/Fisheries } \\
\text { Govemment } \\
\text { General Resident }\end{array}$} & \multicolumn{2}{|c|}{$\begin{array}{l}\text { Business/Tourism } \\
\text { Real Estate/Construction }\end{array}$} & \multicolumn{2}{|c|}{$\begin{array}{l}\text { Environment } \\
\text { Historic/Cultural }\end{array}$} \\
\hline \multicolumn{2}{|c|}{ Problem Category } & Meeting 1 & Meeting 3 & Meeting 1 & Meeting 3 & Meeting 1 & Meeting 3 \\
\hline 1. & $\begin{array}{l}\text { Environmental Protection } \\
\text { Pollution } \\
\text { Waste Treatment } \\
\text { Ground and Surface Water }\end{array}$ & 33.3 & 30.4 & 31.4 & 23.1 & 34.3 & 38.8 \\
\hline 2. & $\begin{array}{l}\text { Development } \\
\text { Amount and Pace } \\
\text { Tourism-related } \\
\text { Zoning Enforcement } \\
\text { Quality Allowed } \\
\text { Infrastructure }\end{array}$ & 37.4 & 28.6 & 33.8 & 32.7 & 36.1 & 28.4 \\
\hline \multicolumn{2}{|c|}{ Subtotals } & 70.7 & 59.0 & 65.2 & 55.8 & 70.4 & 67.2 \\
\hline 3. & Scenic Beauty & 7.2 & 10.7 & 9.7 & 7.7 & 8.6 & 6.9 \\
\hline 4. & $\begin{array}{l}\text { Balance Between Environmental } \\
\text { Integrity and Economic Opportunity }\end{array}$ & 2.1 & 3.6 & 0.9 & 1.9 & 3.5 & 2.6 \\
\hline 5. & Tourism Experience & 1.0 & 3.6 & 0.0 & 7.7 & 0.0 & 4.3 \\
\hline 6. & Historic/Cultural Support & 2.6 & 1.8 & 4.8 & 0.0 & 7.6 & 2.6 \\
\hline 7. & $\begin{array}{l}\text { Other } \\
\text { Government Decisions } \\
\text { Public Involvement } \\
\text { Economics } \\
\text { Recreation } \\
\text { Education } \\
\text { Crime }\end{array}$ & 16.4 & 21.4 & 19.3 & 26.9 & 9.8 & 16.4 \\
\hline
\end{tabular}

period (indicated by the dips in Curves 1 and 3 in Figure 6), that could be perceived as a "disaster" within 25-years.

Evaluation of the Implementation Procedures and the Resulting Models

The model structuring process and the five networks were evaluated by the participants; the situational model was presented to and evaluated by the county planning staff. Both evaluations were performed by the application of questionnaires.

The first questionnaire responses indicated that participants enjoyed taking part in the process, were satisfied with theircontributions, and thought the network diagrams were understandable. They believed that the resulting diagrams identified broad outlooks, reflected consideration of the the most relevant issues and significant relationships, and represented most of their personal concerns as well as those of most interest groups thought to exist in the county. In addition, most participants said that they had learned about the concerns of others, about additional issues previously not considered, and about the complex relationships that exist among the identified issues. Table 2 shows a summary of these results. Comparison of opinions of participants about the importance of issues in the first meeting with their opinions at the end of the third meeting 
(Table 3) confirms these results, since all groups placed importance on a larger number of concerns after taking part in the process. Since these responses did not show major differences by geographic location, interest group affiliation, age, or income, the results were representative of the entire group rather than of a smaller set of individuals.

The results of the second questionnaire indicated that the three members of the County Planning Department found the structural concepts underlying the systems dynamics modeling to be understandable and clear, and the modeling process to be useful in structuring debate and promoting discussion. They also indicated that such modeling could be useful for evaluating alternative policy proposals, provided that all relevant components were included. (Components suggested by the planners were not included, as they had not participated in the modeling because of political expediency.) They conceded, however, that the model could easily be modified to include additional components. The overall opinion was that the approach was a useful tool for the planning profession.

\section{Discussion}

In this paper the principal components of an "integrated" approach to community planning and the results of its first application in Door County, Wisconsin were presented. The main objectives of the approach were: (1) generation of creative options for a new systems design; (2) facilitation of learning through searching for and interpretation of information from facts and values relevant to the situation and acknowledging possible inferential biases; and (3) documentation of the interactions among the various participants, including their negotiations concerning different interpretations of reality, and how these were modified. Further details were given by describing the human actors or participants, the model or representation of the decision environment, and the manner in which the model was developed and used by the participants. The description of these components and selection of appropriate measures corresponding to the above objectives provides the basis of the approach presented here.

The major component of the integrative approach is the representation of the planning situation as perceived by the participants. This representation, referred to as the situational model, becomes a cognitive aid for the participants. The elements of the situational model are attributes of the planning context. The expected outcomes and consequences are the end states to be reached through implementation of alternatives that are feasible combinations of values of the attributes. The model also contains perceived relationships among attributes and between attributes and outcomes. Since model characteristics, its evolution stages, and its evaluation by the participants provide the information base for systematic understanding and procedural improvement, the situational model, including both its design and use, comprises the essence of the integrative approach.

The system dynamics procedure is most appropriate for the implementation of the integrative approach since it may be perceived as the customization of a generic model representing the system as it applies to the planning context.

Here, the notion of a "generic model" refers to the basic structural properties of a class of systems, such as communities. The model may be (1) developed from established theory, (2) discovered inductively by searching for commonalities among models developed by different investigators based on their experience and common sense, or (3) developed by evolution from successive modifications or customizations during the generation of a series of situational models. The main purpose of the generic model is to provide the planning group with a menu of conceptualizations reflecting tentative understandings of potentially relevant subsystems.

Model customization leading to the situational model starts with the integration of the mental models of all participants into a shared structural model. This component of the proposed approach is used to enrich and/or change the generic model. The procedures and the representation media leading to a shared structural model and its subsequent customization are based on assumptions about human thinking and interaction for problem solving.

The three concepts corresponding to the main objectives of cognition, creativity, and social interaction must be operationalized for model evaluation. The present application of the approach shows that the tools designed for model implementation are expected to enhance inferential, ability, judgment, and creativity in participating groups, while the measures developed enable self-evaluation. The procedure also yields a detailed documentation of the planning context, including the actors, the available information and its interpretation, the procedural details, and planning proposals, all of which promote social learning in the long term.

For these reasons, the integrative approach appears to be a promising stategy for community development planning.

\section{References}

Ackoff, R. L. The Art of Problem Solving. New York: John Wiley \& Sons, 1978. "The Art and Science of Mess Management."

Interfaces. 11 (1981). 20-26.

Allen, G. M., and E. M. Gould, Jr. "Complexity, Wickedness 
and Public Forests." Journal of Forestry. (April 1986). $20-23$.

Amabile, T. M.. Social Psychology of Creativity. New York: Springer - Verlag, 1978

Bandler, R., and J. Grinder. Reframing. Moab, : Real People Press, 1982.

Checkland, P. Systems Thinking, Systems Practice. Chichester, England: John Wiley \& Sons, 1981.

Cook, R. J. Soft Systems Thinking for Community Decision Making: A Participative, Computer-Based Modeling Methodology. Ph.D. Thesis. Madison, Wisconsin: University of Wisconsin-Madison, 1987.

Fitz, R. B. "ISM as a Technology for Social Leaming." Portraits of Complexity. M. M. Baldwin, ed. Battelle Monograph No. 9. Columbus, Ohio: Battelle Memorial Institute, 1975.

Forrester, J. Industrial Dynamics. Cambridge, Massachusetts: MIT Press, 1961.

Gill, S. L., and A. Delbecq. "Nominal Group Technique." Group Planning and Problem Solving Methods in Engineering Management. S. A. Olsen, ed. New York: John Wiley \& Sons, 1982.

Hamilton, H. R., S. E. Goldstone, J. W. Milliman, A. L. Pugh III, E. B. Roberts, and A. Zellner. A Systems Simulation for Regional Analysis: An Application to River Basin Planning. Cambridge, Massachusetts: MIT Press, 1969.

Malone, D. W. "Application of ISM: Relating Factors for Urban Success." Portraits of Complexity. M. M. Baldwin, ed. Battelle Monograph No. 9. Columbus, Ohio: Battelle Memorial Institute, 1975.

Martino, J.K. Technological Forecasting for Decision Making. New York: Elsevier, 1972.

Mason, R. O., and I. I. Mitroff. Challenging Strategic Planning Assumptions. New York: John Wiley, 1981.

Mitroff, I. I., and M. Turoff. "The Whys Behind the Hows." IEEE Spectrum. 10 (1973). 62-71.

Mayer, R. E. Thinking, Problem Solving, Cognition. New York: Freeman, 1983.

Nadler, G. "Engineering Research and Design in Socioeconomic Systems." Emerging Methods in Environmental Design and Planning. G. T. Moore, ed. Cambridge, Massachusetts: MIT Press, 1970.

Nisbett, R., and L. Ross. Human Inference: Strategies and Shortcomings of Social Judgement. Englewood Cliffs, New Jersey: Prentice Hall, 1980.

Rickards, T. "Brainstorming." Group Problem Solving Methods in Engineering Management. S. A. Olsen, ed.
New York: John Wiley, 1982.

Rittel, H. W. J., and M. M. Webber. "Dilemmas in a General Theory of Planning." Policy Sciences. 4 (1973). 155-169.

Sancar, F. H. A Model of Planning Methodology for Community Participation and Urban Development. Unpublished Ph.D. Dissertation. University Park, Penn.: Pennsylvania State University, 1977. "System Dynamics as a Heuristic for Systems

Design." Proceedings of the 1983 International System Dynamics Conference at Pine Manor College, Chestnut Hill, Massachusetts, 1983. - "Towards Theory Generation in Landscape Aesthetics." Landscape Journal. 4 (1985). 116-124. "Implementation and Evaluation of a Modeling Approach to Community Development Planning: Meeting the Challenge of Paradigm Breakdown." Proceedings of the International System Dynamics Conference. R. L. Eberlein, ed. Shanghai: People's Republic of China, 1987.

Simon, H. Sciences of the Artificial. Cambridge, Massachusettts: MIT Press, 1969.

Sterman, J. D. "A Skeptic's Guide to Computer Models." Proceedings of the 1985 International Conference of the System Dynamics Society . M. E. Warketin, ed. Keystone, Colorado, 1985.

Vickers, Sir G. The Art of Judgement. New York: Basic Books, 1965.

Waller, R. J. "Application of ISM to Priority Setting in Urban Systems Management." Portraits of Complexity. M. M. Baldwin, ed. Battelle Monograph No. 9. Columbus, Ohio: Battelle Memorial Institute, 1975.

Warfield, J. "TOTOS: Improving Group Problem Solving." Approaches to Problem Solving. No. 3. J. Warfield, ed. Columbus, Ohio: Battelle Memorial Institute and the Academy for Contemporary Problems, 1975. - Societal Systems: Planning, Policy and Complexiry. New York: John Wiley \& Sons, 1976.

Watson, R. H. "ISM-A Useful Tool for Technology Assessment?" Technological Forecasting and Social Change. 11 (1978).

Wilson, H. G. ISM-UNI User Manual. Cedar Falls, Iowa: University of Northern Iowa, 1982.

Woods, M., and G. A. Doeksen. "A Simulation Model for Rural Communities in Oklahoma." Agricultural Experiment Station Bulletin. B-770 (October 1983). Oklahoma City, Oklahoma: Oklahoma State University. 